\title{
POESIA EM TRADUÇÃO: A RESISTÊNCIA TRADUTÓRIA NOS J OGOS DO INVISÍVEL E DO INESPERADO
}

Lauro Maia Amorim

\section{RESUMO}

Este artigo aborda a traduçáo como uma forma de resistência, cujos efeitos do inesperado e do invisível subjazem a minha reinterpretação, em português, de dois poemas da poeta afro-americana contemporânea Harryette Mullen, com interessantes desdobramentos que possibilitam entrever os complexos meandros que caracterizam as diferentes estéticas da negritude.

PALAVRAS-CHAVE: tradução; resistência; poesia

Vejo a tradução como a tentativa de produzir um texto tão transparente que não parece ser traduzido. Uma boa tradução é como uma vidraça. Você só percebe que ela está lá, quando há pequenas imperfeições — arranhōes, bolhas. Idealmente, não deve haver nenhuma. $\mathrm{O}$ vidro nunca deve chamar a atenção para si mesmo.

Norman Shapiro

(Apud KRATZ, 1986, p. 27-28)

\section{Introdução}

ma das formas em que a invisibilidade pode ser relacionada à tradução é através do pressuposto de que os tradutores deveriam ser transparentes em sua prática, atuando apenas como uma vidraça ou uma 
vitrine. Tradutores nunca devem chamar a atenção para o seu trabalho ou para si mesmos, é o que reza a tradição. Não é mera coincidência que a tradução tem sido, há mais de 2000 anos, uma atividade frequentemente subestimada. No entanto, o papel constitutivo desempenhado pelos tradutores na construção do que chamamos de "civilização" seria suficiente para reconhecer que a tradução, na verdade, é, no mínimo, uma atividade visivelmente transformadora. Até mesmo a noção de identidade tradicionalmente pressupóe uma concepção de tradução que, com frequência, depende da possibilidade de que o processo de "identificação" de traduzir o Outro deva ser transparente em si mesmo. Quando associada, por exemplo, com um determinado grupo social, nacional ou étnico (como por exemplo, o "afro-americano" ou o "latino-americano"), espera-se que a identidade seja capaz de traduzir de forma transparente a visibilidade da suposta essência inerente a esses grupos ou naçóes. A partir desse quadro, qualquer abordagem da identidade é baseada na suposição, alicerçada por uma concepção idealizada de responsabilidade, de que a neutralidade e a objetividade na tradução em lidar com o Outro não só são possíveis, como também são requisitos para o exercício da ética. Neutralidade e objetividade são, assim, equivalentes a alguma forma de autoinvisibilidade: espera-se tradicionalmente que a tradução seja objetivamente invisível para que o texto original possa comunicar sua identidade, em outro idioma e cultura, sem distorções, garantindo a visibilidade absoluta do texto de partida. Esse ponto de vista é exemplificado pelos comentários de Norman Shapiro sobre tradução na epígrafe acima. ${ }^{1}$

1 Lawrence Venuti (1995), em seu livro The Translator's Invisibility, lembra-nos de que geralmente se espera que a traduçáo deva ser fluente o suficiente para ser lida como se fosse o próprio texto original. Nos argumentos de Venuti (1995), seria essa "fluência" que conduziria à invisibilidade do tradutor, já que a tradução não deveria, assim, exibir qualquer sinal de opacidade, oferecendo, em vez de disso, apenas uma forma de inteligibilidade acessível. Venuti (1995) afirma que o discurso da fluência apresenta o texto traduzido como se fosse o texto original, quando está, na verdade, apresentando um texto que domestica a estrangeiridade do texto de partida, de modo a aderir às expectativas comercialmente dominantes em busca da fluência. $\mathrm{O}$ autor defende a chamada traduçáo "estrangeirizadora", em vez de uma tradução domesticadora, como um gesto de resistência, na qual o tradutor pode recorrer a formas linguísticas e culturais domésticas que são consideradas marginais em relação às formas linguísticas padrão ou dominantes, levando-o a reconstruir a "estranheza" ou "estrangeiridade" do texto original na língua de recepção. Como forma de resistência, uma tradução "estrangeirizadora" poderia, em tese, perturbar as expectativas por fluência e introduzir novas possibilidades de leitura e de experimentação na cultura de recepção da tradução. Nesse contexto, 
Mesmo se considerarmos a suposta objetividade e transparência de um "painel de vidro", o que é exibido através dele é transformado precisamente pela crença na transparência que ele supostamente evoca: o painel de vidro, como em uma vitrine, confere um valor particular ao que está enquadrado dentro de suas fronteiras decoradas, dentro do quadro das expectativas que a vitrine revela. E a vitrine conclama o espectador de fora da loja a entrar. $\mathrm{O}$ vidro em si interfere na visão do possível consumidor em relação àquilo que é visto, não só fisicamente, como, por exemplo, envolvendo os modos pelos quais a luz incide sobre o vidro e objeto, mas também psicologicamente. $\mathrm{O}$ vidro da vitrine gera um arranjo complexo de percepçóes que coloca em primeiro plano a identidade do consumidor no interior do espaço urbano. Os possíveis clientes podem se ver na vitrine da loja, vendo seus rostos, suas roupas, e imaginar o que interpretam e traduzem a respeito de si mesmos no reflexo. Totalmente integrados ou náo em uma sociedade capitalista, os espectadores da vitrine podem sentir desejo ou pura curiosidade, frustração ou admiração, felicidade ou simplesmente ânsia pelo poder. Qual é a distância entre o seu desejo (possivelmente frustrado) e o objeto desse desejo? Qual é a visibilidade ou invisibilidade econômica com que os clientes se percebem diante da vitrine? Apesar de sua suposta "transparência absoluta", a vitrine certamente desempenha um papel visível e invisível de desencadear um processo de espelhamento social aparentemente inócuo. A vitrine da loja pode nos fazer lembrar dos limites da "propriedade", a distância entre os que possuem e os que não: é possível que não se note que o vidro da vitrine está ali. Também é possível ou não que se tenha consciência do papel social e psicológico eficaz que a vitrine desempenha no jogo entre o visível e o invisível.

Seria possível pensarmos para além dos significados tradicionais de visibilidade e invisibilidade, a fim de refletir sobre a complexa relação simultânea entre o visível e o invisível em jogo na tradução? A noção de resistência à tradução representa outra possibilidade de compreender as relaçôes entre visibilidade e invisibilidade simultâneas no processo de tradução. Essa linha de pensamento, baseada em consideraçôes de Jacques Derrida (2002) sobre a

Venuti (1995) destaca a importância de se ler uma tradução como tradução, uma vez que isso significaria "refletir sobre suas condiçóes, sobre os diferentes discursos e dialetos nacionais em que a tradução é escrita e sobre a situação cultural doméstica na qual ela é lida” (p. 312). 
tradução em Torres de Babel (Des Tours de Babel), informou minhas traduções propostas para alguns poemas de autoria da poeta afro-americana Harryette Mullen, cujo trabalho poético em tradução será discutido neste ensaio. Pretendo analisar a contribuição de Derrida para a compreensão da tradução como transformação, especialmente da relação entre o visível e o invisível na tradução.

\section{A tradução além da comunicação: o (in)visível e o segredo}

Em sua obra Torres de Babel, Jacques Derrida (2002) discorre sobre o mito bíblico de Babel e sobre o ensaio "A tarefa do tradutor", de Walter Benjamin. Derrida demonstra porque a tradução é, ao mesmo tempo, necessária e impossível, ou seja, um double bind. No mito bíblico de Babel, Deus impôs seu próprio nome à tribo dos Shem, que havia começado a construir uma torre por meio da qual poderia impor a sua própria língua ao mundo, como uma língua universal e transparente. Ao impor o seu nome aos Shem, Deus interrompe a construçáo da torre, e os Shem sáo condenados à multiplicidade das línguas.

Como ressalta Derrida (2002),

A "torre de Babel” não configura apenas a multiplicidade irredutível das línguas, ela exibe um não-acabamento, a impossibilidade de completar, de totalizar, de saturar, de acabar qualquer coisa que seria da ordem da edificação, da construçáo arquitetural, do sistema e da arquitetônica. O que a multiplicidade de idiomas vai limitar não é apenas uma tradução "verdadeira", uma entr'expressão [entr'expression] transparente e adequada, mas também uma ordem estrutural, uma coerência do constructum. Existe aí (traduzamos) algo como um limite interno à formalização, uma incompletude da construtura [constructure]. Seria fácil e até certo ponto justificado ver-se aí a tradução de um sistema em desconstrução. (DERRIDA, 1982, p. 11)

Os Shem precisam traduzir a fim de superar as diferenças entre línguas, mas a sua tradução é interrompida, uma vez que não é uma equivalência pura ou uma forma de intercomunicação transparente. O nome de Deus, Babel, é 
tanto um nome próprio como um nome comum que significa "confusão". Tal como acontece com todo nome próprio, Babel resiste à tradução, é intraduzível, mas, ao mesmo tempo, é um nome comum, "confusão", o que quer dizer que se presta à tradução. Como Derrida (1982) esclarece, Deus conclama os Shem à tradução, mas a interrompe:

A tradução de Babel por confusão já é uma tradução incerta e confusa. Traduz-se um nome próprio por um substantivo comum. Deus declara guerra forçando os homens, por assim dizer, a traduzir seu nome próprio por um substantivo comum. Com efeito, ele lhes diz: agora vocês não irão impor uma língua única, vocês serão condenados à multiplicidade das línguas; traduzam e, para começar, traduzam meu nome. Traduzam o meu nome, diz ele, mas, ao mesmo tempo, vocês não serão capazes de traduzir o meu nome, porque, antes de tudo, é um nome próprio e, por outro, o meu nome, que eu mesmo escolhi para esta Torre, significa ambiguidade, confusão, etc. Assim, Deus, em sua rivalidade com a tribo dos Shem, lhes dá, de certa forma, uma ordem absolutamente dupla: Ele impõe um double bind: traduzam-me e, além disso, não me traduzam, desejo que vocês me traduzam, que traduzam o nome que lhes imponho, e, ao mesmo tempo, sobretudo, não o traduzam, vocês não serão capazes de traduzi-lo. (DERRIDA, 1982, p. 137) ${ }^{2}$

O efeito do nome próprio é resultado da intraduzibilidade do idioma, do segredo que resiste em cada texto (em qualquer língua), e que permanece invisível, mas que, paradoxalmente, exige a sua própria tradução ao se integrar na rede de significação do sistema linguístico que torna a leitura, a tradução, a legibilidade e a visibilidade possíveis. A tradução é necessária, mas é em última análise impossível (como transparência ou equivalência pura), o que significa que a tradução pode existir apenas como uma transformação regulada, em vez de um transporte transparente de significados entre línguas. Derrida (1982)

2 As citaçốes para as quais não há uma tradução publicada em português foram por mim traduzidas. 
reflete, assim, sobre o efeito do nome próprio:

Eu diria que esse desejo está em funcionamento em todo nome próprio: traduza-me, não me traduza. Por um lado, não me traduza, isto é, respeite-me como nome próprio, respeite minha lei do nome próprio que está acima de todas as línguas. Por outro lado, traduza-me, ou seja, compreenda-me, preserveme na língua universal, siga minha lei, e assim por diante. Isso significa que a divisáo do nome próprio - na medida em que é a divisão de Deus, e que, por assim dizer, divide o próprio Deus - de certa forma representa o paradigma para o funcionamento do nome próprio. Deus em si mesmo é o double bind, Deus como desconstrutor da Torre de Babel. (DERRIDA, 1982, p. 137)

O mito de Babel é também um relato sobre o sagrado - o nome de Deus é considerado sagrado. E o sagrado é o nome próprio que ao mesmo tempo é traduzido e não se deixa traduzir em nome comum: o nome de Deus é dado à tradução, mas a sua santidade é a sua intraduzibilidade. O sagrado é também o segredo que clama por tradução e, por extensão, todo texto poético é sagrado e secreto: ele demanda tradução, visibilidade e legibilidade, mas a condição do que lhe é sagrado e secreto resiste ao plenamente visível, ao legível, permanecendo sem tradução. Uma vez que a tradução é necessária e impossível, o efeito do nome próprio assume seu lugar no processo de tradução de forma que a resistência a uma tradução definitiva é produzida pela tradução em si ("traduzam-me, mas não me traduzam"). Em outras palavras, a tradução produz tanto o visível quanto o invisível, de modo que a visibilidade ou traduzibilidade provoca a sua própria invisibilidade ou resistência à tradução. A relação entre o invisível e o visível representa o jogo entre novas possibilidades de leitura (de se fazer visível o texto original) e a possibilidade de se multiplicarem os segredos na tradução (como a resistência à tradução em si mesma). Em consonância com as palavras de Paulo Ottoni, "haverá num texto sempre um segredo inanalisável, necessário para que se possa traduzir e se possa ler. Ao traduzir, produzo um outro segredo que a língua impóe para que o texto possa existir e resistir" (OTTONI, 2005, p. 102). 
A tradução multiplica os segredos do texto original ao produzir seus próprios segredos como um ato de transformação. Essa afirmação é particularmente importante quando se trata da tradução que realizei de alguns poemas da poeta afro-americana Harryette Mullen para o português. As diferentes possibilidades de interpretação da mesma passagem de uma tradução - o que é, em parte, resultado da intraduzibilidade de seus poemas gerados pela resistência imposta pela língua — representam "segredos", porque eles não são necessariamente visíveis na tradução e se dão a conhecer (parcialmente) quando se tornam visíveis na potencialidade do não dito da traduçáo, produzido por meio da interpretaçáo. É nesse sentido que compreendo que a tradução da poesia de Harryette Mullen é construída na relação simultânea entre o visível e o invisível, o que vai além da própria noçáo tradicional de comunicação.

A traduçáo não constitui mera "comunicaçáo", já que esta pressupóe, tradicionalmente, a transmissão sem interferências de significados e ideias, enquanto a tradução produz significados, em vez de simplesmente transmiti-los ou conduzi-los, já que representa necessariamente uma "ruptura" regulada em relação ao texto original: não pode simplesmente "transmitir" algo se, de fato, transforma aquilo que supostamente seria "transmitido". Na obra Posiçôes, Derrida ressalta que

nos limites em que ela é possível, em que ela, ao menos, parece possível, a tradução pratica a diferença entre significado e significante. Mas, se essa diferença não é nunca pura, tampouco o é a tradução, e seria necessário substituir a noção de tradução pela de transformação: uma transformação regulada de uma língua por outra, de um texto por outro. (DERRIDA, 2001, p. 26)

Sempre haverá um "resíduo" na tradução, uma relação com aquilo que resiste à tradução definitiva, o que, em outras palavras, resiste à noção de comunicação, em seu sentido tradicional. O leitor não pode se apropriar inteiramente do texto e torná-lo "comunicável"; sempre haverá uma resistência que, em última análise, demanda novas leituras que jamais exaurem tais resíduos: leituras que sempre adiam a possibilidade concreta da comunicaçáo. Considero que o resíduo seja aquilo que resiste à tradução definitiva. Lawrence Venuti, por outro lado, considera o resíduo [remainder] aquilo que "excede os usos 
transparentes da língua orientada para a comunicação e para a referência e pode, de fato, impedi-los, com graus variados de violência" (VENUTI, 1995, p. 216). Venuti assevera que a língua "nunca é simplesmente um instrumento de comunicação, empregado por um indivíduo de acordo com um sistema de regras" (VENUTI, 2002, p. 24). Em vez disso, segundo o autor,

a língua é uma força coletiva, um conjunto de formas que constituem um regime semiótico. Ao circular entre diferentes comunidades culturais e instituiçôes sociais, essas formas estão posicionadas hierarquicamente, com o dialeto padrão em posição de domínio, mas sujeito a constante variação devido aos dialetos regionais ou de grupos, de jargóes, clichês e slogans, de inovaçôes estilísticas, de palavras ad hoc, e a pura acumulação dos usos anteriores. (VENUTI, 2002, p. 24)

Para Venuti, o resíduo também representa uma forma de variação: "qualquer uso da linguagem está sujeito às variaçôes imprevisíveis do resíduo, à força coletiva das formas linguísticas que ultrapassam qualquer controle individual e complicam os sentidos pretendidos" (VENUTI, 2002, p. 207).

É possível afirmar que a resistência à tradução é aquilo que, paradoxalmente, demanda tradução. Ela representa uma "falta" no texto original, que clama pela tradução. O original não é "completo" ou "comunicável": ele requer que a tradução lhe confira uma sobrevida além das línguas. Existe, portanto, uma relação genealógica ou de débito entre o texto original e a tradução, sendo que o texto de partida é o primeiro devedor dessa relação. Fundamentado na leitura do ensaio "A tarefa do tradutor", de Walter Benjamin, Derrida considera que

O original é o primeiro devedor, o primeiro demandador, ele começa por faltar - e por lastimar após a tradução. Essa demanda não é apenas do lado dos construtores da torre que querem se fazer um nome e fundar uma língua universal se traduzindo dela mesma; ela também obriga o desconstrutor da torre: dando seu nome, Deus também invocou a tradução, não apenas entre as línguas tornadas subitamente múltiplas e confusas, 
mas primeiramente de seu nome, do nome que ele clamou, deu e que deve traduzir-se por confusão para ser entendido, portanto, para deixar entender que é difícil traduzi-lo e assim entendê-lo. No momento em que ele impóe e opóe sua lei àquela da tribo, ele é também demandador de tradução. Ele também está endividado. Ele não parou de lastimar após a tradução de seu nome, ao passo que ele mesmo a interdita. Pois Babel é intraduzível. Deus lamenta sobre seu nome. Seu texto é o mais sagrado, o mais poético, o mais originário posto que ele cria e se dá um nome, e não fica por isso menos indigente em sua força e em sua própria riqueza, ele clama por um tradutor. (DERRIDA, 2002, p. 40-1)

O tradutor é um sujeito endividado, obrigado por um dever, ocupando uma posição de herdeiro. O tradutor enfrenta a demanda pela tradução imposta pelo texto original: "traduza-me." Por outro lado, o tradutor, como Derrida explica, é o "agente da sobrevivência”. O tradutor torna possível a sobrevivência dos nomes dos autores e de suas assinaturas. Nas palavras de Derrida, "tal sobrevida dá um pouco mais de vida, mais que sobrevivência. A obra não vive apenas mais tempo, ela vive mais e melhor, acima dos meios de seus autores" (DERRIDA, 2002, p. 33). A dívida do tradutor não implica que ele ou ela deverá restituir uma cópia ou uma boa imagem, nem uma representação fiel do original. Bem como Derrida ressalta, "o original se dá modificando-se, esse dom náo é de um objeto dado, ele vive e sobrevive em mutação" (DERRIDA, 2002, p. 38).

Uma representação fiel do original não pode ser restituída porque o original está em transformação. A falta no texto original exige mutação e sobrevivência - haverá sempre ruptura e diferença na origem e a tradução multiplica as diferenças no processo de sobrevivência, apesar da identificação convencional entre o texto original e a tradução. As diferenças multiplicadas pela tradução não devem ser vistas como um fracasso, mas como uma inevitável (des) continuação do texto original em mutação.

A tradução dos poemas de Harryette Mullen, especialmente da obra Muse \& Drudge, representa a disseminação de significados na diferença, além da pura visibilidade do texto original. Nesse sentido, o original na tradução 
torna-se simultaneamente visível e invisível, traduzido e não traduzido. Considero que tanto a intraduzibilidade quanto a traduzibilidade, o visível e o invisível, o inteligível e, ao mesmo tempo, a resistência à inteligibilidade são aspectos constitutivos da escrita poética de Mullen em tradução. Cada poema traduzido produz o seu próprio modo de expressáo disjuntiva. Assim como no jazz, em que a inteligibilidade e a experimentação imprevistas se meclam, a relação simultânea entre conexões invisíveis e inesperadas e os contornos visíveis daquilo que se espera é o que molda a experiência estética única de traduzir a poesia de Harryette Mullen.

\section{A tradução de Muse \& Drudge ("musa \& mula") 3 de Harryette Mullen: os meandros da negritude e do (in)esperado}

Harryette Mullen é uma poeta e pesquisadora afro-americana. Nasceu em Florence, Alabama, mas foi criada em Fort Worth, Texas. Atualmente é professora de literaturas americana e afro-americana na Universidade da Califórnia, em Los Angeles. Sua estreia como poeta se deu no início dos anos 80, com a publicação de seu primeiro livro de poesias, Tree Tall Woman, em 1981. Só viria a publicar seu próximo livro dez anos mais tarde, com Trimmings, em 1991 (reeditado em Recyclopedia), seguido de $S^{*} P e R M^{* *} K^{*} T$ (1992, e reeditado em Recyclopedia), e de Muse \& Drudge (1995, também reeditado em Recyclopedia). O livro Blues Baby, Early Poems, de 2002, é uma publicação de seus primeiros poemas até então não coligidos, e Sleeping with the Dictionary, também de 2002, é seu livro de poesias mais recente, tendo sido indicado para os prêmios National Book Award, National Book Critics Circle Award, e o Los Angeles Times Book Prize. Recentemente, a autora recebeu o prêmio Jackson Prize de poesia e o Gertrude Stein Award de poesia inovadora. A respeito de Mullen, Elizabeth Frost constata que

cruzando fronteiras entre campos estéticos frequentemente isolados, Harryette Mullen é pioneira de sua própria forma de poesia lírica disjuntiva e bluseada, combinando preocupaçóes

3 Musa \& Mula sugere um trocadilho com dois sentidos possíveis: "musa e mula”, mas também "musa emula". 
com questôes suscitadas por políticas de identidade com ênfase pós-estruturalista na linguagem. Mullen desafia as opiniôes predominantes acerca dos cânones da poesia contemporânea, buscando chamar atenção, em especial, para as tradiçôes marginalizadas do experimentalismo afro-americano do qual sua escrita emerge. As influências sobre seu trabalho incluem desde Gertrude Stein ao Black Arts Movement, de Sapho a Bessie Smith, do movimento Language poetry ao rap. Os textos lúdicos e alusivos de Mullen vêm atraindo uma atenção cada vez maior nos últimos anos, talvez pelo próprio fato de que eles sejam, com frequência, difíceis de categorizar. Em seu modo particular de abordar a poética, Mullen promove importantes interrogaçóes acerca da tradição, da inovação e da identidade cultural. (FROST, 2012, p. 231-32) ${ }^{4}$

Ao discutir a relação entre identidade e poesia no trabalho de Harryette Mullen, Kate Percy afirma que

Harryete Mullen tem um interesse particular pelo poder mnemônico da rima e do ritmo, dos jingles de propaganda, letras de música, declamação de poesia, cançôes e rimas infantis. Ela concebe sua relação com a poesia como um projeto de reciclagem ou de recuperação da língua padronizada; no entanto, posiciona conscientemente seu trabalho não contra, mas em relação aos discursos mnemônicos da tecnologia contemporânea e da cultura do commodity. [...] Mullen satiriza

4 Language poetry refere-se ao tipo de poesia produzida pelo grupo originalmente conhecido como " $\mathrm{L}=\mathrm{A}=\mathrm{N}=\mathrm{G}=\mathrm{U}=\mathrm{A}=\mathrm{G}=\mathrm{E}$ poets", em referência à revista publicada com o mesmo nome. O grupo surgiu no final dos anos 60 e início dos 70, e foi altamente influenciado pela tradição americana modernista, particularmente de Gertrude Stein e Louis Zukofsky, além de poetas como Barret Watten, Silliman Ron e Charles Bernstein, entre outros. Eles passaram a ser conhecidos como um movimento de vanguarda na poesia estadunidense, representando um exemplo do pós-modernismo poético em que a escrita em si desafia as expectativas tradicionais pela presença evidente de um eu lírico subjacente ao texto, enfatizando, assim, a disjunçáo e a materialidade dos significantes do poema. 
o status sobredeterminado do clichê e do estereótipo por meio da recitação nonsense. [...] Ela realça efeitos irônicos ao produzir leves alteraçóes em expressôes e palavras familiares. O trabalho de Mullen performa as dissonâncias da língua e do som, provocando a investigação das convençôes poéticas da coerência e das construçóes culturais da identidade. (PERCY, 2012)

Poderíamos talvez ler o título Muse \& Drudge como referência à Musa que oferece o sonho de uma identidade pura, mas não alcançável, e que inspira poetas, escritores, compositores e blues men. É também uma alusão à serviçal, à mula (the Drudge), como a passividade que dá chão ao sonho. É o caminho "mastigado", batido, que conduz ao sonho inalcançável da Musa. Mas a Musa é ela mesma a serviçal, a mula. É a relação entre a imagem pública da mulher-musa do blues e do jazz e a figura desgasta, da mulher abandonada à sua própria sorte em meio à sua solidão e às vicissitudes de uma diva. Em um de seus poemas, "what you do to me", Harryette Mullen apresenta-nos um verso particularmente jocoso: "ketchup with reality". O trocadilho que está em jogo entre os homófonos "ketchup" ("um tempero") e "catch up with" ("alcançar"), em justaposição com a palavra "reality" ("realidade”), desencadeia questóes de identidade, subjetividade e discurso: ser um "sujeito" é estar na condição de quem está sujeito a forças, regras sociais e impulsos, mas que, também, se coloca como a fonte ou origem de uma ação.

O sujeito, no entanto, não pode evitar ser o próprio objeto da sua subjetividade construída, e não supostamente intocada e imutável. Em conexão com esse raciocínio, os poemas de Harryette Mullen deslocam os limites que muitas vezes moldam a construção da identidade da poética afro-americana como um discurso reconhecível e desejável sobre a negritude. Em seu ensaio intitulado The cracks between what we are and what we are supposed to be: stretching the dialogue of African-American Poetry ("As rachaduras entre o que somos e que se espera que sejamos: ampliando o diálogo da poesia afro-americana”), Harryette Mullen (2012) busca questionar essa percepção:

o discurso sobre "outras negritudes" [other blackness] (e não sobre a "alteridade negra" [black otherness]) tem se deslocado recentemente para uma discussáo mais ampla em torno da mul- 
tiplicidade e da dissonância - a outra face da unidade ou da homogeneidade — das identidades e culturas afro-americanas. [...] A interrogação exploratória da identidade negra como uma formação discursiva, cultural e social suscita questôes críticas acerca das representaçóes convencionais da identidade negra, permitindo que os significados da negritude proliferem e se expandam, ampliando a identidade negra e tornando-a mais inclusiva; mas, também, permitindo a instabilidade na definição do que seja negritude. (MULLEN, 2012, p. 68)

A relação entre inclusão e instabilidade permeia a textualidade alusiva de Muse \& Drudge. Nas palavras de Elizabeth Frost,

as composiçôes associativas de Mullen trazem à luz não a aleatoriedade, mas a inesperada similitude — entre significantes, os conceitos que eles representam e as experiências que possibilitam construir [...] Em seus textos profundamente lúdicos, Mullen deixa a língua revelar uma miríade de associaçôes inesperadamente familiares. (FROST, 2002, p. 406)

Harryette Mullen refamiliariza expressóes idiomáticas e referências culturais do universo afro-norte-americano no contexto dos sabores e dissabores da globalização. Seu trabalho de experimentação poética revitaliza as discussōes acerca das dimensões estéticas da negritude e os lugares da sujeição e da visibilidade do sujeito. Sua poesia inclui retratos das tensóes estéticas, sociais e raciais, com também as infindas possibilidades crítico-poéticas de se relerem as relaçóes entre linguagem e realidade e de como identidades são formadas, deslocadas e instituídas. O trabalho de Mullen, tanto como poeta, quanto como pesquisadora, torna ainda mais complexos os intervalos que constituem o próprio campo discursivo da estética literária afro-americana, ao enfatizar sua hibridez e ao ampliar suas próprias fronteiras. Se a poesia de Mullen poderia ser concebida como "ampliando" a identidade negra e tornando-a mais inclusiva, bem como permitindo que a instabilidade participe da definição do que seja "negritude", isso significa que ela é um conceito em constante construção. Se levarmos a sério que não há nenhuma auten- 
ticidade branca ou negra real, mas uma construção ideológica, histórica e estética acerca de discursos culturais, torna-se claro que não há uma origem pura anterior aos conflitos ideológicos que buscam afirmar um discurso de identidade da negritude.

A própria identidade é uma tradução (ou várias traduções) de uma herança cultural, mas a herança em si só pode ser conhecida através das leituras da identidade, em outras palavras, através da tradução. A forma altamente lúdica e experimental da poesia de Mullen, que alcançou um público diversificado nos EUA, conduzindo a diferentes reaçóes, requer uma tradução que seja capaz de, simultaneamente, ser aceitável e responder ludicamente às demandas do texto original. Por outro lado, precisamente porque a tradução se inscreve em novas referências culturais e novos trocadilhos, as interpretaçóes que emergem a partir de uma leitura do texto em português podem atingir horizontes inesperados, mesmo que a tradução em si seja baseada em argumentos aceitáveis. $\mathrm{O}$ que não se pode impedir de se tomar lugar na tradução, mesmo quando se recorre ao "cálculo" da interpretação? De que maneira certo “(des)cálculo" pode se relacionar com a identidade, com a negritude e com a noção do (in)visível na tradução? O que significa se engajar em possibilidades miríades que não apontam para um alvo fixo ou previsível, mesmo quando se levam em consideração os limites e coerçóes de qualquer tradução?

A fim de responder a essas perguntas, pretendo discutir minhas traduções de dois poemas de Harryette Mullen, extraídos de Muse \& Drudge, que foram selecionados porque exemplificam os diferentes aspectos relacionados à questão do (in)visível no processo de tradução. Mesmo se a tradução se destina a ser uma leitura aceitável do poema original, ela possibilita interpretaçóes que não são, necessariamente, um resultado de uma estratégia de tradução intencional e calculada. Especialmente quando se trata de traduzir trocadilhos, mesmo a combinação mais calculada entre palavras e sons não pode impedir que o leitor produza novas associaçóes. Dirk Delabastita afirma que "o jogo de palavras é tradicionalmente definido como uma estratégia comunicativa deliberada, ou o resultado dela, usado com um efeito semântico ou pragmático específico em mente" (DELABASTITA, 1997, p. 6, grifos meus). O que se questiona, no entanto, é até que ponto um ato deliberado e intencional de criação de um novo trocadilho na tradução, por mais formalmente "idêntico" 
ao trocadilho original, poderia garantir os mesmos efeitos de ambiguidade na cultura alvo da tradução? Delabastita, de certa forma, reconhece a dificuldade imposta por essa pergunta:

empiricamente falando, é bastante óbvio que nem toda palavra em todo texto é um trocadilho múltiplo, ou certamente não na mesma medida, ou da mesma forma, que os trocadilhos que claramente se destacam para um amplo círculo de leitores. Em todas as comunidades linguísticas e práticas discursivas parecem existir limites específicos para o poder associativo da língua. Qual é a natureza precisa desses limites à livre associação e à ambiguidade infinita? Perguntas como essas desafiam uma resposta fácil, mas reconhecer sua pertinência é um primeiro passo. (DELABASTITA, 1997, p. 6)

Há, certamente, limites sociais à interpretação, mas não podemos sempre prever esses limites para todos os casos, ou qual a sua amplitude em contextos diferentes. Mesmo que eu assevere conhecer os aspectos linguísticos que constituem um jogo de palavras no texto original, não posso garantir exatamente o mesmo efeito do trocadilho correspondente na tradução. Embora minha tradução dos poemas de Mullen tenha por objetivo fornecer uma leitura minimamente aceitável do texto original, ela necessariamente desencadeia interpretações diferentes, e até mesmo contraditórias, a depender da formação dos leitores, da sua experiência cultural, e da sua habilidade de resposta ao "deslize semântico" que a tradução evoca. Leituras inesperadas são, portanto, produzidas pela proliferação dos efeitos do (in)visível na tradução, o que pode ser explorado no poema a seguir, "the sun goes on shinning", cujos versos sugerem cenas de violência contra a mulher e a imagem de um homem cujo poder físico é ironicamente minimizado: 
sun goes on shining

while the debbil beats his wife

blues played lefthanded

topsy-turvy inside out

under the weather

down by the sea

a broke johnny walker

mister meaner

bigger than a big man

cirrus as a heart attracts

more power than a loco motive

think your shit don't stink

edge against a wall

wearing your colors

soulfully worn out

stylishly distressed

(MULLEN, 2006, p. 103) o sol brilha contra a garoa

o belzeburro surra sua garota

um blues de canhoto

o avesso do avesso do avesso

bem baqueado

à beira-mar

um johnny walker quebrado

Dom de Lito

maior que o maioral

tão sérreo que o coração se farta

mais potente que loco motiva

achar a tua merda não fedida

beirada contra a parede

vestindo tuas cores

de alma surrada

e dissabor refinado

De acordo com Clarence Major, a expressão "[The] Devil is beating his wife" ("O demônio está batendo em sua esposa"), no saber popular afro-americano, refere-se ao momento em que "o sol aparece quando está chovendo" (MAJOR, 1994, p. 134). Além disso, "acreditava-se que se enfiasse uma caneta no chão e colocasse o ouvido ali seria possível ouvir os socos” (MAJOR, 1994, p. 134). No poema, a palavra "devil" é ligeiramente modificada com a inserção de um duplo "bb" (em "debbil"), transformando o diabo em uma criatura "debilitante". Em português, "belzeburro" é uma combinação entre "Belzebu" e "burro". No entanto, a expressão idiomática subjacente a "um dia chuvoso, mas com sol", como se o diabo "estivesse batendo em sua mulher" continua intraduzível. Essa é a razão pela qual a palavra "garoa”, no primeiro verso, foi selecionada, a fim de estabelecer uma ligação entre "chuva" e "sol". Por outro lado, "garoa" inesperadamente permite desencadear uma memória cultural compartilhada entre muitos brasileiros, especialmente da cidade de Sáo Paulo, que, tradicionalmente, ficou conhecida como a "terra da garoa”. Uma interpretação que se soma ao poema, na forma da memória, e que surge inesperadamente, 
é a referência ao tradicional grupo de samba da cidade de São Paulo, ativo há muitas décadas: os Demônios da Garoa, que, por sinal, é um "link" que pode se desdobrar a partir da presença indireta de "belzebu" no verso. A relaçấo com o samba nesse verso não é uma suposição clara ou objetiva, mas, pelo contrário, é uma possibilidade do (in)visível, uma vez que a tradução desdobra o não dito, o segredo que resiste à plena resoluçáo, mas que pode se fazer visível como um (des)cálculo inesperado, trazido à tona pela interpretação.

$\mathrm{O}$ verso "a broke johnny walker" pode se referir a "uma garrafa de whisky quebrada" tanto quanto à imagem de um homem bêbado e "quebrado". Em seguida, "mister meaner" ("senhor malvado") sugere um trocadilho em que se lê, por semelhança de sons, "misdemeanor" ("pequeno delito"). "Dom de Lito" sugere um "nome próprio", que, por outro lado, se revela como um "nome comum" ("delito"), além de produzir um "resíduo" inesperado de ironia ao associar a memória subjacente de "Dom Juan" ("o bom de cama") a gestos delituosos.

"Topsy-Turvy", no quarto verso, pode significar "confuso" ou "de cabeça para baixo", além de poder ser interpretado como uma alusão a uma personagem escrava do romance Cabana do Pai Tomás, de Harriet Beecher Stowe. Seu nome era "Topsy" porque a personagem costumava desafiar muitos dos modos e costumes das mulheres brancas. Essa passagem é exemplar do problema da intraduzibilidade, uma vez que é difícil, se não impossível, recriar a mesma referência literária em Português, embora o romance já tenha sido traduzido no Brasil. Essa é a razão pela qual decidi pôr em evidência uma alusão diferente, mantendo uma relação semântica semelhante à "Topsy Turvy", traduzido por "avesso do avesso do avesso", um verso da canção "Sampa", de Caetano Veloso. A cançáo, composta como um choro, descreve o sentimento paradoxal de se viver em São Paulo, apontando para questóes relacionadas à pobreza, à riqueza, à poesia e à esperança, tanto para as Américas quanto para a África. Na cançẫo de Caetano lê-se: "Pan-Americas de Áfricas utópicas" e um "novo quilombo de Zumbi".

"Cirrus as a heart attracts" pode ser lido como "(A nuvem) Cirro (é) como o coração (que) atrai", soando como "serious as a heart attack" ("sério como um ataque do coração"). Em português, "tão sérreo que o coração se farta" envolve outra ambiguidade: "sérreo" ("montanhoso") se aproxima sonoramente de "sério", e a expressão "coração se farta" é similar a "coração se 
enfarta”. Novas associações são produzidas na tradução, que não se reduz a um cálculo previsível que supóe a igualdade entre as partes (original e tradução), mas a um (des)cálculo que busca lidar com a ambiguidade e com as relaçóes inesperadas de sentido que a poesia de Harryette Mullen é capaz de produzir no contexto da língua inglesa.

O poema foi traduzido de forma a se aproximar tanto quanto possível do texto original, mas, assim como no caso da "vitrine" mencionada no início do texto, o poema traduzido "refrata" o texto original, elaborando novas conexóes (in)visíveis que vão além das expectativas em busca de um "reflexo" direto ou de uma equivalência pura ou restrita: o poema traduzido suscita outras associaçóes que ampliam as possibilidades de interpretação para novos horizontes, enriquecendo os campos expressivos do poema em inglês, no território das relaçôes culturais brasileiras. O próximo poema, "ifyour complexion is a mess", sugere a voz autoritária da indústria mundial de cosméticos, que oferece clareamento como a "soluçáo" para os negros:

if your complexion is a mess our elixir spells skin success you'll have appeal bewitch be adored hechizando con crema dermoblanqueadora

what we sell is enlightenment nothing less than beauty itself since when can been in the dark what shines hidden in dirt

double dutch darky take kisses back to Africa they dipped you in a vat at the wacky chocolate factory

color we've got in spades melanin gives perpetual shade though rhythm's no answer to cancer pancakes pale and butter can get rancid (MULLEN, 2006, p. 132) se sua tez é miscelânea em excesso nosso elixir traz a pele do sucesso vai ter o apelo sedutor ser adorado hechizando con crema dermoblanqueadora

o que vendemos é esclarecimento nada menos que a beleza em si desde quando é pra ficar no escuro o que brilha oculto na sujeira

neguinho bom bom manda negrescos de volta pra África te mergulharam num tanque na fantástica fábrica de chocolate

cor temos pra dar com pá sombra perpétua na melanina dá mas ritmo não assola a pele cancerosa pó compacto é pálido e a manteiga rançosa 
Poderíamos interpretar o poema como sugerindo que os negros não são bem-vindos, quase como se fossem estrangeiros diante de uma escolha: ou você embranquece, se quiser permanecer na América, ou "volta” para a África. O poema pode ser lido como uma irônica apologia ao branqueamento, uma vez que poderia ser interpretado como a voz da indústria globalizada de cosméticos. A presença do espanhol no poema faz o processo de clareamento soar como mercadoria global. Outra interpretação possível pode ser motivada pela existência de toda uma indústria de cosméticos focada em ambos os mercados afro-americanos e latinos nos Estados Unidos.

O verso "take kisses back to Africa" apresenta mais sutilezas do que parece. "Kisses", além de significar "beijos", é também o nome de docinhos de chocolate em forma de "gota" da marca Hersheys, presenteadas durante as comemoraçóes de Natal e do dia dos namorados nos Estados Unidos. Metaforicamente, a palavra "kisses" também pode se referir aos negros que deveriam ser enviados de volta para a África. Seria uma alusão ao movimento "Back to Africa”, também conhecido como "movimento de colonização", que se originou nos Estados Unidos no século XIX e que encorajava afro-americanos a migrar para o continente africano. A ambiguidade de "kisses", no poema, impóe desafios para sua tradução. Uma possível solução é a tradução de "kisses" por "beijinhos", que se refere a um tipo de doce muito popular em festas de aniversário. O problema é que "beijinhos" são geralmente brancos porque são feitos de coco. Haveria uma alternativa: no Brasil temos um biscoito recheado conhecido como "negresco", que seria uma versão do "Oreo" norte-americano. O verso em inglês foi traduzido por "manda negrescos de volta para a África”. Ao fazer isso, é possível que o leitor faça a ligação entre o biscoito de chocolate, e os negros que, associados a esse chocolate, "deveriam" ser enviados de volta para a África.

É interessante que, nos Estados Unidos, o termo Oreo é usado como gíria para se referir aos afro-americanos "assimilados" que, seriam "pretos por fora e brancos por dentro", já que o biscoito, de chocolate, tem recheio branco de baunilha. Mesmo que "kisses", um termo chave no poema, não tenha sido traduzido por "beijos", vale ressaltar que "negresco" produz associaçóes semelhantes, mas também inesperadas, além do "cálculo" tradutório, e igualmente interessantes na língua portuguesa. O fato de que o biscoito "negresco" é branco por dentro e preto por fora, tal como "Oreo", pode ser lido de forma diferente por afro-brasileiros politicamente engajados, que criticam a ausência de conscienti- 
zação política entre muitos brasileiros afrodescendentes. A esse respeito, uma vez que nunca houve qualquer movimento "de volta para África” no Brasil, o verso em português pode até ser lido como uma voz solitária contrária à voz dominante do "sistema" colonizador de branqueamento, representada pela indústria de cosméticos ao longo do poema. É como se dissesse aos negros "brancos por dentro" para voltarem para a África e aprender com suas raízes culturais ou, em outras palavras, se "reafricanizar". Essa interpretação é possível porque as estrofes não são estritamente vinculadas a uma única leitura: um verso pode oferecer uma voz diferente que se eleva em contraste com outras do poema. A tradução, nesse sentido, prolifera "conexóes (in)visíveis" do poema de Mullen, oferecendo novas possibilidades de associaçóes que vão além da ideia de "comunicabilidade" do texto, já que não segue um padrão de previsibilidade, ou seja, de um cálculo que seja capaz de apagar os "resíduos" ou "restos" que se impóe como formas de resistência à plena inteligibilidade ou visibilidade do texto. Essas conexôes demandam do leitor o envolvimento com outras possibilidades de compreender os versos de maneiras imprevisíveis e incalculáveis. Essa é uma forma de resistência à interpretação definitiva, o que também é uma "resistência à tradução" que se inscreve na própria tradução. O leitor se enreda na relação entre o visível e os aspectos invisíveis que se inscrevem na "vitrine" tradutória do poema.

\section{Tradução, poesia e negritude: (des)continuidade, resistência e transformação}

Como dito anteriormente, a tradução representa uma (des)continuação do texto original, que sobrevive em sua mutação em outro idioma. Especialmente em relação aos poemas de Mullen em tradução, essa (des)continuidade é construída sobre a relação entre o que é visível e o non-dit do invisível em português, que demanda interpretaçóes e deslizamentos semânticos. A poesia de Mullen joga com ambivalências e referências culturais, bem como conexôes semânticas inesperadas que exigem uma forma igualmente experimental de tradução para produzir um espaço de continuidade e descontinuidade do original. Os poemas traduzidos (des)continuam os poemas originais no sentido de que experimentam com outras conexóes semelhantes, mas igualmente inesperadas. As novas conexóes criadas pela tradução abrem espaço para pensar e questionar diferentes aspectos que não são menos importantes do que 
as que estão em jogo no texto original. A tradução de "kisses" por "negrescos" promove uma dupla leitura em que duas vozes conflitantes estão em jogo na tradução: a voz da indústria de cosméticos e uma nova voz, aquela representada pelos afrodescendentes politicamente engajados no Brasil. Se é possível interpretar a indústria cosmética como troçando dos negros, sugerindo que "devem ser enviados de volta para a África”, também é possível encontrar, na tradução, uma voz adicional que inesperadamente problematiza o discurso de branqueamento ao criticar ironicamente os afro-brasileiros, por assim dizer, "assimilados". A riqueza da poesia de Mullen reside precisamente nas possibilidades de interpretação que um leitor informado é capaz de produzir em relação às alusôes e conexôes semânticas que produz. As relações criadas em português não apenas refletem uma tentativa de recriar, na tradução, as ambivalências dos poemas de Mullen, mas elas também apontam para a resistência à tradução na própria tradução, abrindo novos horizontes de interpretação que enriquecem as possibilidades de compreensão de um texto original em sua relação crítica com referências culturais e ideológicas do texto alvo.

A poesia contemporânea de Harryette Mullen é um exemplo, entre outros de poetas afrodescendentes contemporâneos, que representa a busca de se traduzir poeticamente as complexidades da negritude. Sou particularmente interessado na lógica que governa essa forma de "tradução", vinculada a uma relação entre o traduzível e a resistência à própria tradução. A traduzibilidade (da poética) da negritude se refere às diferentes formas em que, historicamente, ela tem sido lida e interpretada (por diferentes poetas) no sentido de veicular/transformar determinados significados culturais e representar interesses sociais. No entanto, a (poética da) negritude também resiste ao ato de tradução. É justamente essa resistência que clama por tradução, por leituras que nunca esgotam ou apropriam definitivamente a textualidade da (poética da) negritude como uma formação discursiva. As diferenças multiplicadas pela tradução representam uma resistência a uma tradução definitiva. A esse respeito, quando se trata da noção de negritude na poesia, vale a pena observar não apenas as formas em que a negritude resiste a uma tradução definitiva, mas também como cada poema (como uma forma de representação dela) é uma (des)continuação da (poética da) negritude. Ou, em outras palavras, é precisamente o processo de descontinuidade que representa a transformação inevitável da negritude enquanto fenômeno de diversidade social e cultural internacional. 


\section{Referências}

DELABASTITA, Dirk. (Ed). Essays on punning and translation. Manchester: St. Jerome, 1997.

DERRIDA, Jacques. Torres de Babel. Tradução Junia Barreto. Belo Horizonte: Editora UFMG, 2002.

. Posiçôes. Tradução Tomaz Tadeu Silva. Belo Horizonte: Autêntica, 2001.

. L'oreille de l'autre: otobiographies, transferts, traductions. Montréal: VLB Éditeur, 1982.

FROST, Elisabeth. An interview with Harryette Mullen. MULLEN, H. The cracks between what we are and what we are supposed to be. Tuscaloosa: University of Alabama Press, 2012.

. Harryette Mullen's "Recyclopedia”. RANKINE, C; SPAHAR, J. (Orgs.) American women poets in the $21^{\text {st }}$ century: where lyric meets language. Middletown Connecticut: Wesleyan University Press, 2002.

KRATZ, Denis. An interview with Norman Shapiro, Translation Review, v.19, n. 1, p. 27-28, 1986. Special Issue: Medieval Literature.

MULLEN, Harryette. Tree tall woman. Energy Earth Press, 1981.

Recyclopedia: Trimmings, $\mathrm{S}^{*} \mathrm{PeRM}^{* *} \mathrm{~K}^{*} \mathrm{~T}$ and Muse \& Drudge. Saint Paul: Graywolf Press, 2006.

. Blues baby, early poems. Lewisburg: Bucknell University Press, 2002.

. Sleeping with the dictionary. Los Angeles: University of California Press, 2002.

.The cracks between what we are and what we are supposed to be: stretching the dialogue of African-American poetry. . The cracks between what we are and what we are supposed to be. Tuscaloosa: University of Alabama Press, 2012.

MAJOR, Clarence. Juba to jive: a dictionary of African-American slang. New York: Penguin, 1994.

OTTONI, Paulo. A tradução manifesta: double bind e acontecimento. Campinas: Editora da Unicamp, 2005. 
PERCY, Kate. A poetics of opposition?: race and the avant-garde. Modern American Poetry, http://web.archive.org/web/19980128170629/http://english.rutgers.edu/pierce.htm, 20/01/2012.

VENUTI, Lawrence. The translator's invisibility: a history of translation. New York: Routledge, 1995.

. Escândalos da tradução. Tradução Laureano Pelegrin, Lucinéia Marcelino Villela, Marileide Dias Esqueda e Valéria Biondo. Bauru: Edusc, 2002

\title{
POETRY IN TRANSLATION: THE TRANSLATORIAL RESISTANCE AT PLAY IN THE REALM OF THE INVISIBLE AND THE UNEXPECTED
}

\begin{abstract}
This essay addresses translation as a form of resistance, whose invisible, unexpected effects underlie my rendering into Portuguese of two poems by the AfricanAmerican contemporary poet Harryette Mullen, with interesting developments that enable to envisage the complex intricacies that characterize different black aesthetics.
\end{abstract}

KEYWORDS: translation; resistance; poetry

Recebido em: 12/08/2013 Aprovado em: 10/09/2013 